\title{
Morphometric Study of Nuclei in FNAC of Breast Lesion and its Role in Diagnosis of Malignancy
}

\section{Dibyajyoti Boruah $^{1 *}$, V Srinivas ${ }^{1}$ and SG Belagavi ${ }^{2}$}

${ }^{1}$ Department of Pathology, Armed Forces Medical College, Pune-411040, Maharashtra, India

${ }^{2}$ Graded Pathologist, 164-Military Hospital, C/O 99 APO, Binnaguri, Jalpaiguri-735232, West Bengal, India

\begin{abstract}
Introduction: Cytological features obtained from fine needle aspiration cytology(FNAC) are very essential for the preoperative diagnosis in breast carcinoma. The quantitative evaluation of nuclear size and shape using FNAC material can be utilized as a diagnostic tool in breast tumor. The main objectives of our study were (a) to evaluate major axis (MAJX), minor axis (MINX), nuclear area (NA), nuclear perimeter (NP) and nuclear aspect ratio (NAR) using morphometric techniques, (b) to compare these nuclear parameters with their variability in benign and malignant cases and evaluate suitable cut off values and (c) to study the correlation of these parameters with cytological grades.
\end{abstract}

Materials and Methods: Nuclear parameters were assessed in 50 cases of invasive ductal carcinoma and 50 cases of benign breast tumors by image morphometric technique on FNAC slides and statistical analysis was performed.

Results: Mean MAJX, MINX, NA, NP and their variability were significantly greater $(p<0.001)$ in malignant cases than the benign unlike NAR. All nuclear parameters showed positive correlation with their variability. Cytological grade exhibited mild positive correlation with MAJX, MINX, NA and NP except NAR. The cut off values with sensitivity=1.00 for the differentiation of malignant from benign were: (a) MAJX>10.70 micron (specificity=0.98), (b) MINX $>7.53$ micron (specificity=0.94), (c) NA>60.61 micron $^{2}$ (specificity=0.98) and (d) NP>27.81 micron (specificity=0.96).

Conclusion: Morphometric parameters related to nuclear size and variability evaluated from FNAC material were significantly larger in malignant cases than the benign and they can be gainfully exploited in the diagnosis of breast carcinoma. Again these parameters showed mild positive correlation with the cytological grades.

Keywords: Breast tumor; FNAC; Nuclear parameters; Morphometric analysis

\section{Introduction}

Breast cancer is a malignant disease which is the most common and frequent cause of cancer-induced deaths in women. Globally, it accounts for $22 \%$ of all cancers occurred in females; out of which about $80 \%$ are invasive ductal carcinomas (IDCs). Carcinoma of the breast comes out also leading cause of cancer related morbidity and mortality in Indian women population. Methodical early detection through screening, effective investigative pathways and optimal treatment have the ability to lessen current breast cancer mortality rates $[1,2]$. A fine needle aspiration cytology (FNAC) sample or needle core biopsy (NCB) specimen is commonly used for the pathological assessment. FNAC is relatively noninvasive, simple and economical procedure, which has been used for over a century [3-5]. It is of enormous diagnostic potential in the preoperative assessment of breast tumors [6]. Though FNAC has great potential to diagnose breast carcinoma satisfactorily, but it is quite difficult to determine the exact tumor type and grade [7].

The nuclear morphometric study is one way to understand about the tumors and grades. During the past several years, it has been well established that several clinical, cytological and histopathological variables are helpful in predicting the clinical outcome of cancer patients. Currently, computer-assisted image morphometry provides a new influential tool for high-precision measurement of several variables, characterising the size and shape of nuclei. A number of these nuclear parameters appear to be useful prognostic predictors in various human malignancies. The nuclear size is usually larger in cancer cells. Hence, image morphometric analysis could be very useful supplement to regular FNAC for further grading and appropriate treatment of the patient [7-10]. Morphometric aspects which describe size and shape of cells and nuclei could be utilized for determination of tumor type [11-14].

In our present work, the nuclear morphometric study was performed on the breast FNAC slides to investigate distinction between benign tumor and malignant lesion of IDC. The main objective of our study was:

(a) To evaluate major axis (MAJX), minor axis(MINX), nuclear area(NA), nuclear perimeter(NP) and nuclear aspect ratio (NAR) using morphometric techniques,

(b) To compare these nuclear parameters and their variability in benign and malignant cases for the determination of cut off values with specificity, sensitivity and efficiency; and

(c) To study the correlation of nuclear parameters with cytological grades.

*Corresponding author: Dibyajyoti Boruah, Scientist- 'D', Department of Pathology, Armed Forces Medical College, Pune - 411040, Maharashtra, India, Tel: 91-20-26306025; E-mail: dibyajyotibh@yahoo.co.uk

Received July 08, 2014; Accepted August 31, 2014; Published September 02, 2014

Citation: Boruah D, Srinivas V, Belagavi SG (2014) Morphometric Study of Nucle in FNAC of Breast Lesion and its Role in Diagnosis of Malignancy. J Cytol Histol 5 : 274. doi:10.4172/2157-7099.1000274

Copyright: $\odot 2014$ Boruah D, et al. This is an open-access article distributed under the terms of the Creative Commons Attribution License, which permits unrestricted use, distribution, and reproduction in any medium, provided the original author and source are credited. 
Citation: Boruah D, Srinivas V, Belagavi SG (2014) Morphometric Study of Nuclei in FNAC of Breast Lesion and its Role in Diagnosis of Malignancy. J Cytol Histol 5: 274. doi:10.4172/2157-7099.1000274

Page 2 of 7

\section{Materials and Methods}

The present study included 50 cases of invasive ductal carcinoma and 50 cases of benign tumor of breast that were managed at this tertiary care institute during 2009-2012. Cases of adequate FNA material were selected. In all the cases FNAC was performed as pre diagnosis procedure; and slides were stained with routine Papanicolaou method. The smear was evaluated by pathologist to classify benign and malignant cases. Robinson's grading was used for the cytological grading of malignant tumors [8-10]; where the cases were divided into three cytological grades: grade-I, grade-II and grade-III. In this grading system, six cytological features: a) cell dissociation, b) nuclear size, c) cell uniformity, d) nucleoli, e) nuclear margin and f) chromatin pattern were considered and for each features score was given from 1 to 3 , then summed up all the six scores. Depending on the total score the grading was done: grade-I had score 1-11; grade-II had score 12-14; grade-III had score 15-18 [8,9]. There were 10 cases of grade-I, 29 cases of gradeII and 11 cases of grade-III tumors.

\section{Nuclear morphometry}

Nuclear morphometric analysis was performed on PAP stained FNAC slide by using a computerized digital photomicrograph and image analyzing system [15]. The system was properly calibrated for each digital magnification and resolution. For each sample five high power field (400X) was digitally recorded. For determination of nuclear parameters, nuclei which edges were not overlapped with another were chosen. To get the nuclear parameters: the chosen nuclei of a recorded image were rounded with the cursor, then digitally selected all the rounded nuclei, finally clicked on selected nuclei and then the software automatically measured their parameters (Figure 1). This way, nuclear parameters were determined for 100 nuclei for each sample. After measurement, the data was transferred to MS-Excel sheet for further analysis. Nuclei were analyzed for MAJX, MINX, NA, NP and NAR. NAR was defined as the ratio of the long axis to the short axis of a nucleus; an elongated nucleus takes larger value of NAR. All morphometric assessments were performed by one observer without information of cytological diagnosis.

\section{Statistical analysis}

The various parameters used to analyze were MAJX, MINX, NA, NP and NAR for each nucleus of every sample; the mean values of each sample with standard deviation (SD) were evaluated. SD of the nuclear parameters: SD- MAJX, SD-MINX, SD-NA, SD-NP and SDNAR were considered as the variability of that parameter for a sample. The mean values of the parameters with SD and range were calculated for the two groups: benign and malignant. Similarly, the mean values of the parameters with SD and range were determined for the three cytological grades of the malignant tumors. Student's $t$ test and oneway ANOVA were been performed to calculate $p$ values. Data was reported as mean, SD and range of mean for these parameters. The statistical correlations of the analyzed morphometric parameters with their variability for all samples; and cytological grades of all malignant samples were investigated. Pearson correlation coefficient (' $r$ ') and $p$ value were calculated, and regression line was drawn in correlation studies. Receiver operating characteristics (ROC) curve between sensitivity and (1-specificity) were evaluated for MAJX, MINX, NA and NP to estimate cut off values between benign and malignant cases. In this study, the decision given by the pathologist based on FNAC result was considered as gold standard for the estimation of sensitivity and specificity for the cut off values.

The distributions of the measured nuclear parameters of benign and malignant samples were also examined.

\section{Results}

The mean values of nuclear parameters and age with SD and range for benign and malignant groups with $\mathrm{p}$ values between them are presented in the Table 1 . The mean values of variability of five nuclear morphometric parameters with range for benign and malignant groups

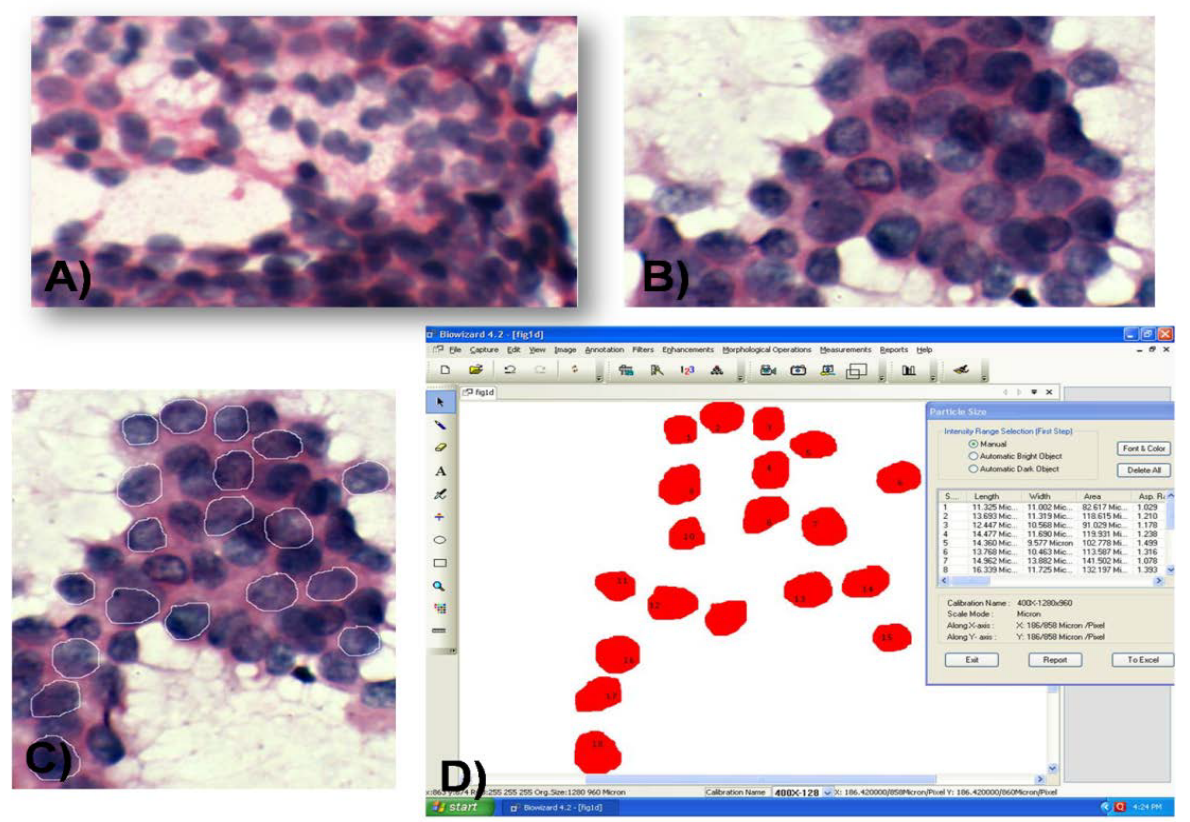

Figure 1(A-D): Photo micrograph of benign (A) and malignant(B) FNAC sample (400 X magnification). Rounding of the nuclear boundary (C) and measurement of nuclear parameters (D) using Biowizard 4.2 software. 


\begin{tabular}{|c|c|c|c|c|}
\hline SL no & Parameters (unit) & Benign $(n=50)$ & Malignant $(n=50)$ & $p$ value \\
\hline 1 & $\begin{array}{l}\text { Age } \\
\text { (year) }\end{array}$ & $\begin{array}{c}30.8 \pm 10.5 \\
(13-59)\end{array}$ & $\begin{array}{c}51.4 \pm 10.15 \\
(30-76)\end{array}$ & $<0.001^{*}$ \\
\hline 3 & $\begin{array}{c}\text { MAJX } \\
(\mu \mathrm{m})\end{array}$ & $\begin{array}{c}8.98 \pm 0.64 \\
(7.44-10.22)\end{array}$ & $\begin{array}{l}13.30 \pm 1.91 \\
(10.08-19.02)\end{array}$ & $<0.001^{*}$ \\
\hline 3 & $\begin{array}{l}\text { MINX } \\
(\mu \mathrm{m})\end{array}$ & $\begin{array}{l}6.93 \pm 0.51 \\
(5.68-8.03)\end{array}$ & $\begin{array}{l}10.58 \pm 1.42 \\
(7.66-14.15)\end{array}$ & $<0.001^{*}$ \\
\hline 4 & $\begin{array}{c}\mathrm{NA} \\
\left(\mu \mathrm{m}^{2}\right)\end{array}$ & $\begin{array}{c}49.34 \pm 6.79 \\
(33.15-62.47)\end{array}$ & $\begin{array}{l}113.25 \pm 31.92 \\
(60.83-213.68)\end{array}$ & $<0.001^{*}$ \\
\hline 5 & $\begin{array}{l}\mathrm{NP} \\
(\mu \mathrm{m})\end{array}$ & $\begin{array}{c}24.98 \pm 1.76 \\
(20.60-28.13)\end{array}$ & $\begin{array}{c}37.49 \pm 5.18 \\
(27.85-52.07)\end{array}$ & $<0.001^{*}$ \\
\hline 6 & NAR & $\begin{array}{c}1.30 \pm 0.05 \\
(1.21-1.40)\end{array}$ & $\begin{array}{l}1.28 \pm 0.06 \\
(1.16-1.43)\end{array}$ & 0.056 \\
\hline
\end{tabular}

values are expressed as: mean \pm standard deviation (minimum value - maximum value), $\mathrm{n}=$ number of sample, ${ }^{*}$-difference is significant

Table 1: The mean values of Age and five nuclear morphometric parameters with $S D$ and range for benign and malignant groups with $p$ values (using unpaired Student's t-Test) between them.

\begin{tabular}{|c|c|c|c|c|}
\hline SL no & Parameters (unit) & Benign $(n=50)$ & Malignant $(n=50)$ & $p$ value \\
\hline 1 & SD-MAJX $(\mu \mathrm{m})$ & $\begin{array}{c}1.16 \\
(0.71-1.59)\end{array}$ & $\begin{array}{c}1.86 \\
(1.05-3.21)\end{array}$ & $<0.001^{*}$ \\
\hline 3 & SD-MINX $(\mu \mathrm{m})$ & $\begin{array}{c}0.99 \\
(0.72-1.35)\end{array}$ & $\begin{array}{c}1.55 \\
(0.96-2.51)\end{array}$ & $<0.001^{*}$ \\
\hline 3 & SD-NA $\left(\mu \mathrm{m}^{2}\right)$ & $\begin{array}{c}10.67 \\
(7.45-14.32)\end{array}$ & $\begin{array}{c}27.61 \\
(13.76-61.01)\end{array}$ & $<0.001^{*}$ \\
\hline 4 & SD-NP $(\mu \mathrm{m})$ & $\begin{array}{c}2.71 \\
(1.88-3.83)\end{array}$ & $\begin{array}{c}4.45 \\
(2.88-7.53)\end{array}$ & $<0.001^{*}$ \\
\hline 5 & SD-NAR & $\begin{array}{c}0.22 \\
(0.16-0.32)\end{array}$ & $\begin{array}{c}0.21 \\
(0.13-0.31)\end{array}$ & 0.095 \\
\hline
\end{tabular}

values are expressed as: mean (minimum value - maximum value), $\mathrm{n}=$ number of sample, *-difference is significant

Table 2: The mean values of variability of five nuclear morphometric parameters with range for benign and malignant groups with $p$ values (using unpaired Student's $\mathrm{t}$-Test) between them. The standard deviation of a nuclear parameter of a sample is considered as the variability of that parameter for that sample. with $\mathrm{p}$ values are presented in the Table 2 and Figure 2A-F represent the distribution of studied samples of benign and malignant groups with Age, MAJX, MINX, NA, NP and NAR. Distribution of malignant samples for the first five studied parameter were clearly shifted towards the larger values than the benign samples unlike NAR.

\section{Benign}

The mean age of the benign group was 30.8 year (range: 13 year- 59 year). In this group, mean MAJX was $8.98 \mu \mathrm{m}$ (range: $7.44 \mu \mathrm{m}-0.22$ $\mu \mathrm{m})$ and the mean MINX was $6.93 \mu \mathrm{m}$ (range: $5.68 \mu \mathrm{m}-8.03 \mu \mathrm{m}$ ). The mean values of NA and NP were $49.34 \mu \mathrm{m}^{2}$ (range: $33.15 \mu \mathrm{m}^{2}-62.47$ $\mu \mathrm{m}^{2}$ ) and $24.98 \mu \mathrm{m}$ (range: $20.60 \mu \mathrm{m}-28.13 \mu \mathrm{m}$ ) respectively. The mean NAR was 1.30 (range: 1.21-1.40). In this group, mean SD-MAJX was $1.16 \mu \mathrm{m}$ (range: $0.71 \mu \mathrm{m}-1.59 \mu \mathrm{m}$ ) and the mean SD-MINX was 0.99 $\mu \mathrm{m}$ (range: $0.72 \mu \mathrm{m}-1.35 \mu \mathrm{m}$ ). The mean values of SD-NA and SD-NP were $10.67 \mu \mathrm{m}^{2}$ (range: $7.45 \mu \mathrm{m}^{2}-14.32 \mu \mathrm{m}^{2}$ ) and $2.71 \mu \mathrm{m}$ (range: 1.88 $\mu \mathrm{m}-3.83$ ) respectively. The mean SD-NAR was 0.22 (range: $0.16-0.32$ ).

\section{Malignant}

The mean age of the malignant group was 51.4 year (range: 30 year76 year), which was significantly higher than the benign group. In this group, mean MAJX was $13.30 \mu \mathrm{m}$ (range: $10.08 \mu \mathrm{m}-19.02 \mu \mathrm{m}$ ) and the mean MINX was $10.58 \mu \mathrm{m}$ (range:7.66 $\mu \mathrm{m}-14.14 \mu \mathrm{m}$ ). The mean values of NA and NP were $113.25 \mu \mathrm{m}^{2}$ (range: $60.83 \mu \mathrm{m}^{2}-213.68 \mu \mathrm{m}^{2}$ ) and $37.49 \mu \mathrm{m}$ (range: $27.85 \mu \mathrm{m}-52.07 \mu \mathrm{m}$ ) respectively. The mean NAR was 1.28 (range: 1.16-1.43). In this group, mean SD-MAJX was $1.86 \mu \mathrm{m}$ (range: $1.05 \mu \mathrm{m}-3.21 \mu \mathrm{m}$ ) and the mean SD-MINX was $1.55 \mu \mathrm{m}$ (range: $0.96 \mu \mathrm{m}-2.51 \mu \mathrm{m})$. The mean values of SD-NA and SD-NP were 27.61 $\mu \mathrm{m}^{2}$ (range: $13.76 \mu \mathrm{m}^{2}-61.01 \mu \mathrm{m}^{2}$ ) and $4.45 \mu \mathrm{m}$ (range: $2.88 \mu \mathrm{m}-7.53$ ) respectively. The mean SD-NAR was 0.21 (range: 0.13-0.31).Except NAR and SD-NAR, the mean of other parameters in malignant group were significantly higher $(\mathrm{p}<0.001)$ than the benign group.
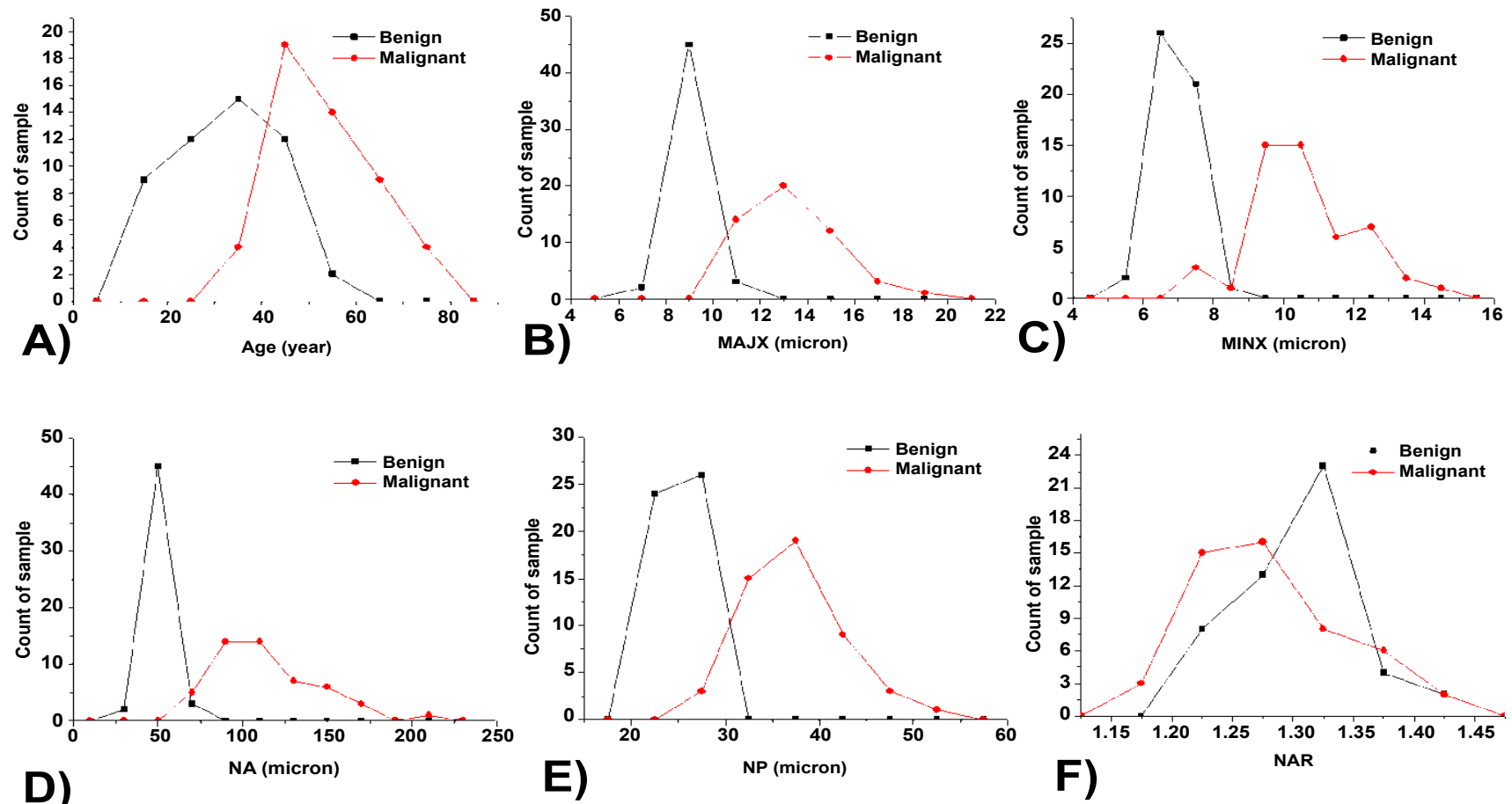

Figure 2(A-F): The distribution of studied samples of benign and malignant groups with: A) Age, B) MAJX, C) MINX, D) NA, E) NP and F) NAR. 
Citation: Boruah D, Srinivas V, Belagavi SG (2014) Morphometric Study of Nuclei in FNAC of Breast Lesion and its Role in Diagnosis of Malignancy. J Cytol Histol 5: 274. doi:10.4172/2157-7099.1000274

\section{Correlation with variability}

Figure 3A-E represent scatter plots of mean MAJX, MINX, NA, $\mathrm{NP}$ and NAR versus their variability (SD) for all benign and malignant samples with linear regressions. Variability of the parameters showed strong positive correlation with their mean value for MAJX $(\mathrm{r}=0.835)$, MINX ( $\mathrm{r}=0.838)$, NA ( $\mathrm{r}=0.948)$ and $\mathrm{NP}(\mathrm{r}=0.854)$; but showed moderate positive correlation for NAR ( $\mathrm{r}=0.568)$. We have seen two different clusters of benign and malignant samples in the first four scatter plots Figure 3A-D.

\section{Distribution of nuclear parameters in a sample}

The distribution pattern of the size related nuclear parameters in a sample was similar for both the malignant and benign tumors. But the benign tumors have smaller SD and range in their distribution than the malignant tumors. Figure $4 \mathrm{~A}, \mathrm{~B}$ stand for nuclear area distributions for five benign and five malignant cases respectively; where malignant samples have larger range and SD of NA than the benign.

\section{ROC curves and cut off values}

The nuclear parameters related to size showed remarkable distinction between the benign and malignant tumors. Hence this information can be used to identify malignant tumors. Receiver operating characteristics (ROC) curves between sensitivity and (1-specificity) with cut off values and efficiency were evaluated for mean MAJX, MINX, NA and NP and presented in Figure 5A-D. The cut off values with sensitivity 1(100\%) for the differentiation of malignant from benign were: (a) MAJX $>10.70$ micron (specificity=0.98), (b) MINX $>7.53$ micron (specificity=0.94), (c) NA $>60.61$ micron $^{2}$ (specificity $=0.98$ ) and (d) NP> 27.81 micron (specificity=0.96).
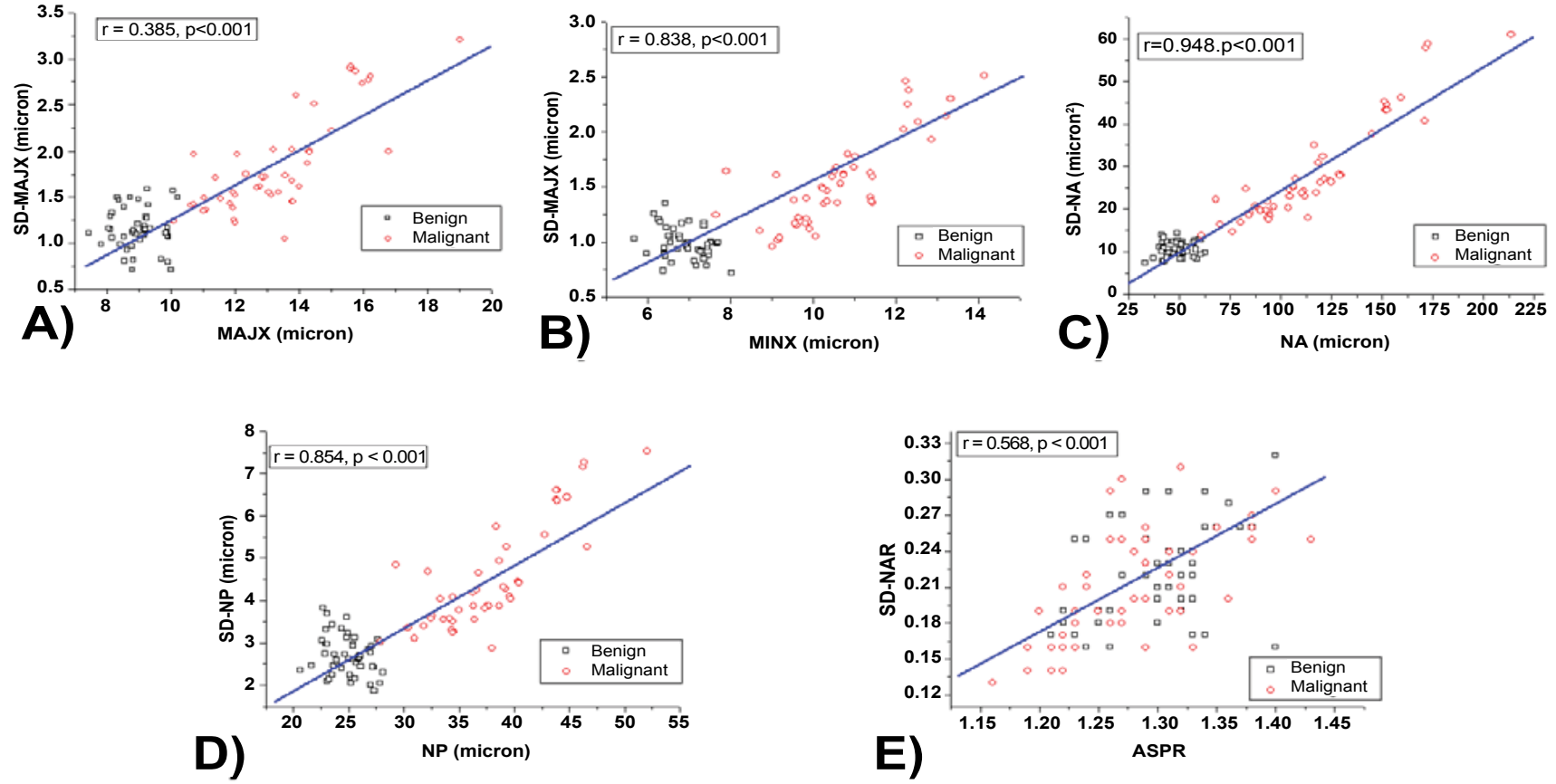

Figure 3(A-F): Scatter plot of mean : A) MAJX; B) MINX; C)NA; D)NP; E)NAR with their SD (variability) for all benign and malignant samples; linear regression of these parameters with their $\mathrm{SD}$ are shown by the solid lines in their respective plot.

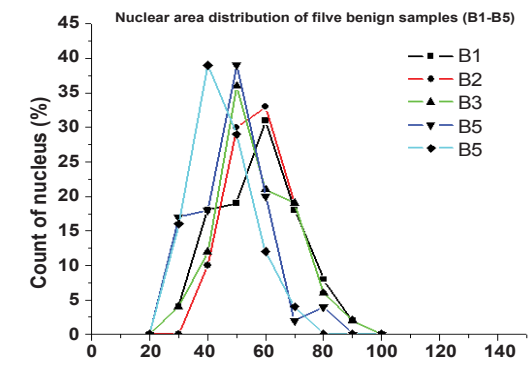

A)

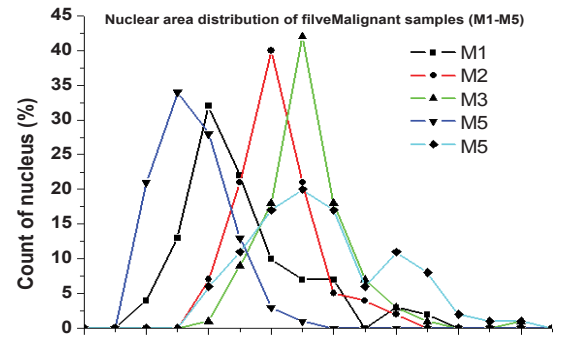

B)

NA (micron $\left.{ }^{2}\right)$

Figure 4 (A-B): The measured distribution of nuclear area for : A) five samples (B1, B2, B3, B4, B5) of the benign group; B) five samples (M1, M2, M3, M4, M5) of the malignant group. 


\section{Cytological grades}

The mean values of nuclear parameters and age with SD and range for the three malignant groups with $\mathrm{p}$ values between each pair are presented in the Table 3. One-way ANOVA test showed that the three grades were different from each other for the nuclear parameters $(\mathrm{p}<0.05)$.

\section{Correlation with cytological grades}

Figure 6A-E represent scatter plots of MAJX, MINX, NA, NP and NAR versus cytological grades for all malignant samples with linear regressions. Cytological grade showed mild positive correlation with

\begin{tabular}{|c|c|c|c|c|c|}
\hline SL no & $\begin{array}{c}\text { Parameters } \\
\text { (unit) }\end{array}$ & $\begin{array}{l}\text { Grade-I } \\
(n=10)\end{array}$ & $\begin{array}{c}\text { Grade-II } \\
(n=29)\end{array}$ & $\begin{array}{c}\text { Grade-III } \\
(n=11)\end{array}$ & $p$-value \\
\hline 1 & $\begin{array}{l}\text { Age } \\
\text { (yrs) }\end{array}$ & $\begin{array}{c}51.6 \pm 10.2 \\
(38-72)\end{array}$ & $\begin{array}{c}52.5 \pm 8.8 \\
(39-70)\end{array}$ & $\begin{array}{c}48.5 \pm 13.5 \\
(30-76)\end{array}$ & 0.547 \\
\hline 3 & $\begin{array}{c}\text { MAJX } \\
(\mu \mathrm{m})\end{array}$ & $\begin{array}{c}12.87 \pm 1.82 \\
(10.08-15.97)\end{array}$ & $\begin{array}{c}12.93 \pm 1.76 \\
(10.12-19.02)\end{array}$ & $\begin{array}{c}14.67 \pm 1.90 \\
(10.72-16.79)\end{array}$ & $0.023^{*}$ \\
\hline 3 & $\begin{array}{c}\text { MINX } \\
(\mu \mathrm{m})\end{array}$ & $\begin{array}{c}9.95 \pm 1.37 \\
(7.66-12.55)\end{array}$ & $\begin{array}{l}10.44 \pm 1.18 \\
(7.71-14.15)\end{array}$ & $\begin{array}{l}11.51 \pm 1.72 \\
(7.91-13.33)\end{array}$ & $0.027^{*}$ \\
\hline 4 & $\begin{array}{c}\text { NA } \\
\left(\mu \mathrm{m}^{2}\right)\end{array}$ & $\begin{array}{l}102.62 \pm 28.60 \\
(60.83-159.28)\end{array}$ & $\begin{array}{l}108.13 \pm 28.30 \\
(60.89-213.68)\end{array}$ & $\begin{array}{l}136.41 \pm 35.14 \\
(67.79-172.53)\end{array}$ & $0.019^{*}$ \\
\hline 5 & $\begin{array}{l}\mathrm{NP} \\
(\mu \mathrm{m})\end{array}$ & $\begin{array}{c}35.82 \pm 4.94 \\
(27.85-44.78)\end{array}$ & $\begin{array}{c}36.69 \pm 4.56 \\
(27.91-52.07)\end{array}$ & $\begin{array}{c}41.11 \pm 5.66 \\
(29.27-46.57)\end{array}$ & $0.025^{\star}$ \\
\hline 6 & NAR & $\begin{array}{l}1.33 \pm 0.06 \\
(1.24-1.43)\end{array}$ & $\begin{array}{l}1.26 \pm 0.05 \\
(1.16-1.38)\end{array}$ & $\begin{array}{l}1.28 \pm 0.04 \\
(1.22-1.33)\end{array}$ & $0.001^{*}$ \\
\hline
\end{tabular}

values are expressed as: mean \pm standard deviation (minimum value - maximum value), $\mathrm{n}$ - number of sample, *-difference is significant

Table 3: The mean values of Age and five nuclear morphometric parameters with SD and range for the three cytological grades with $p$ values (using one-way ANOVA) to determine differences between the means of the parameters of three grades.
$\operatorname{MAJX}(\mathrm{r}=.317), \operatorname{MINX}(\mathrm{r}=0.364), \mathrm{NA}(\mathrm{r}=0.353)$ and $\mathrm{NP}(\mathrm{r}=0.341)$ and weak negative correlation with NAR $(r=-0.245)$.

\section{Discussions}

Presently, routine FNAC technique is very popular as a preoperative assessment in breast lesion because of its high efficiency, sensitivity and specificity [8-10]. Nuclear morphometric parameters in malignant cases of breast tumor were distinctly larger than the benign, which could be utilized in diagnosis for the distinction of the groups [1114]. The association of nuclear size with the diagnosis of malignancy was also previously studied by various researchers [16-20]. Our study also showed that the information of mean NA, NP, MAJX and MINX and their standard deviation can be gainfully used to make decision in diagnostics with high precision. The SD of the size related parameters is a quantitative measure of nuclear pleomorphism, which was significantly higher in malignant cases. Though the distribution patterns of size related nuclear area in a sample in both the groups were almost similar, the ranges and SD of NA were larger in the malignant than the benign cases. However NAR and SD-NAR, the parameters related to mean shape and its variability, did not show significant difference between malignant and benign cases, hence this parameter is not useful for demarcation like Abdalla et al. [11]. Further it was observed that the mean Age in the malignant cases was significantly higher than the benign. The nuclear parameters depicted sized showed strong positive correlation with their variability. The size related nuclear parameters showed mild positive correlation with cytological grades also.

Abdalla et al. [11] studied 40 cases of breast tumor (17 benign and 23 malignant) in Libyans using morphometric technique, and showed that size related nuclear parameters were very important for decision making. They evaluated cut off value for mean nuclear area
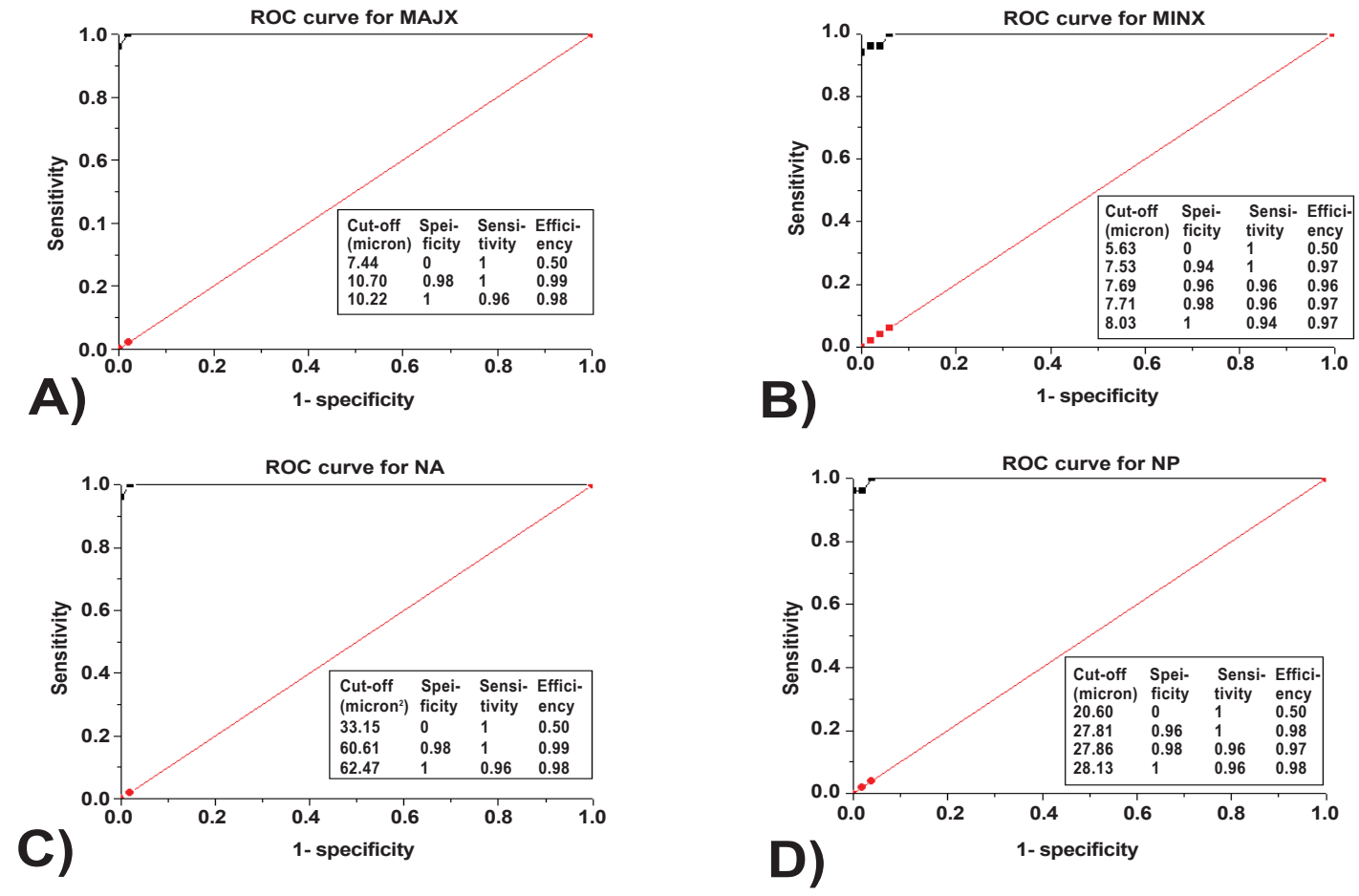

Figure 5(A-D): ROC curve used to determine cut off for malignancy for A) MAJX, B) MINX, C) NA and D) NP. 

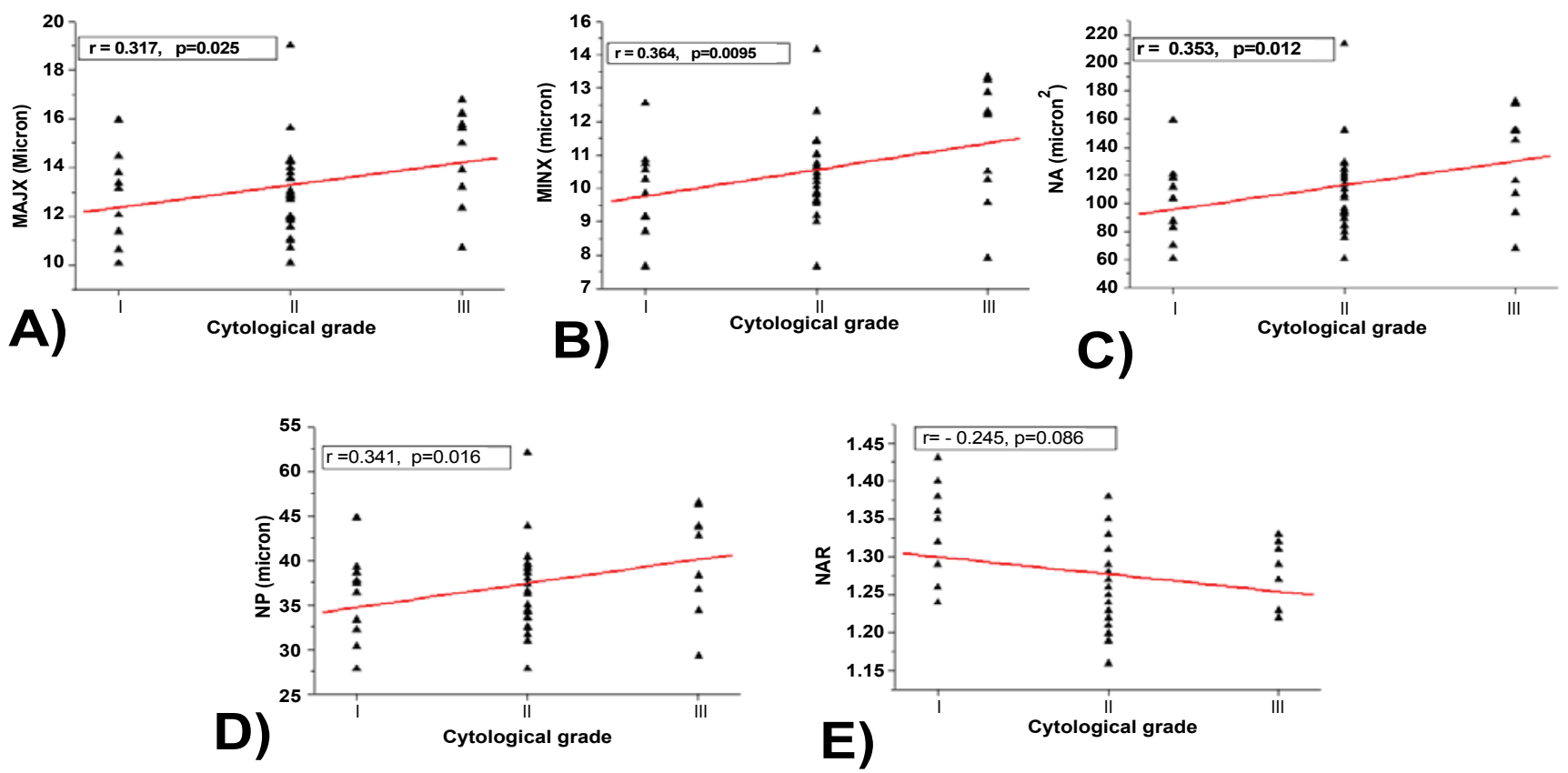

Figure 6(A-F): Scatter plot of Cytological grade versus: A) MAJX; B) MINX; C)NA; D)NP and E)NAR ; linear regression of these parameters with grades are shown by the solid lines in their respective plot.

diagnostic purposes; for $100 \%$ detection of malignant cases: $\mathrm{NA}>54$ $\mu \mathrm{m}^{2}$ (specificity $84 \%$ ), for $100 \%$ detection of benign cases: $\mathrm{NA}<72 \mu \mathrm{m}^{2}$ (sensitivity $91 \%$ ). The maximum efficiency of their method was $97.4 \%$ for the detection of malignancy.

Our study was performed in Indian and we considered routine FNAC technique was gold standard and observed that, for the detection of malignancy, all four size related parameters were equally powerful with high efficiency, but MAJX and NA displayed the best with maximum efficiency 99\% (MAJX $\left.>10.70 \mu \mathrm{m}, \mathrm{NA}>60.61 \mu \mathrm{m}^{2}\right)$. Hence, there is a possibility to develop an automatic system to evaluate mean MAJX and NA from the FNAC slide, which could be incorporated as a new way for the screening of breast carcinoma. Centers, where large number of such samples come, this method will be very useful and may reduce the load of the concerned pathologist.

Distribution of size related nuclear parameters of a malignant sample was distinctly different from the benign one. The range and $\mathrm{SD}$ of size related nuclear parameters in a malignant sample was much larger the benign one. Hence variability of nuclear size in a sample can also be utilized for diagnosis purpose.

The size related nuclear parameters of the malignant samples were different from each other and exhibited mild positive correlation with cytological grade. But it was not suitable for the grading of the malignant samples using the nuclear parameters alone; since the ranges of three cytological grades were overlapping.

In conclusion, it is suggested that the nuclear morphometric parameters related to nuclear size were significantly larger in malignant than the benign and they can be gainfully exploited as a substitute indicator in diagnosis of malignancy in breast carcinoma, which has high sensitivity and specificity. These results can be used for the automatic screening of malignancy in breast FNAC, with help of smart image recognition software which can automatically select the correct boundary of a nucleus. But these parameters were not enough for the grading of the malignant samples alone. Nuclear parameters related to size showed mild positive correlation with the cytological grades and moderate positive correlation with Age which can facilitate a better understanding of the tumor biology. Further, there is a scope of morphometric study to correlate of FNAC results with histo-pathological diagnosis in breast tumors in a larger sample size which would be better for making decision in surgical procedure.

\section{Acknowledgement}

Authors acknowledge Mr D R Basannar, Scientist-F of Department of Community Medicine, AFMC for his valuable suggestion in statistical analysis and paramedical staff of Department of Pathology, AFMC for their support in preparation of the slides.

\section{References}

1. Pinder SE, Elston CW, Ellis IO (1996) The role of pre-operative diagnosis in breast cancer. Histopathology 28: 563-566.

2. Lamb J, Anderson TJ, Dixon MJ, Levack PA (1987) Role of fine needle aspiration cytology in breast cancer screening. J Clin Pathol 40: 705-709.

3. Spriggs Al (1977) History of cytodiagnosis. J Clin Pathol 30: 1091-1102.

4. Frable WJ (1989) Needle aspiration biopsy: past, present, and future. Hum Pathol 20: 504-517.

5. Bukhari MH, Arshad M, Jamal S, Niazi S, Bashir S, et al. (2011): Use of FineNeedle Aspiration in the Evaluation of Breast Lumps. Patholog Res Int.

6. Denley H, Pinder SE, Elston CW, Lee AH, Ellis IO (2001) Preoperative assessment of prognostic factors in breast cancer. J Clin Pathol 54: 20-24.

7. PrvuloviÄ I, Kardum-Skelin I, SusterciÄ $S$ (2010) Morphometry of tumor cells in different grades and types of breast cancer. Coll Antropol 34: 99-103.

8. Robinson IA, McKee G, Nicholson A, D’Arcy J, Jackson PA, et al. (1994) Prognostic value of cytological grading of fine-needle aspirates from breas carcinomas. Lancet 343: 947-949. 
Citation: Boruah D, Srinivas V, Belagavi SG (2014) Morphometric Study of Nuclei in FNAC of Breast Lesion and its Role in Diagnosis of Malignancy. J Cytol Histol 5: 274. doi:10.4172/2157-7099.1000274

9. Khan N, Afroz N, Rana F, Khan M (2009) Role of cytologic grading in prognostication of invasive breast carcinoma. J Cytol 26: 65-68.

10. Das AK, Kapila K, Dinda AK, Verma K (2003) Comparative evaluation of grading of breast carcinomas in fine needle aspirates by two methods. Indian J Med Res 118: 247-250.

11. Abdalla F, Boder J, Buhmeida A, Hashmi H, Elzagheid A, et al. (2008) Nuclear morphometry in FNABs of breast disease in Libyans. Anticancer Res 28: 39853989 .

12. Radwan MM, Amer KA, Mokhtar NM, Kandil MA, El-Barbary AM, et al. (2003) Nuclear Morphometry in Ductal Breast Carcinoma with Correlation to Cell Proliferative Activity and Prognosis. Journal of the Egyptian Nat. Cancer Inst 15: $169-182$

13. Mapstone NP, Zakhour HD (1990) Morphometric analysis of fine needle aspirates from breast lesions. Cytopathology 1: 349-355.

14. Tan PH, Goh BB, Chiang G, Bay BH (2001) Correlation of nuclear morphometry with pathologic parameters in ductal carcinoma in situ of the breast. Mod Pathol 14: 937-941.
15. Boruah D and Deb P (2013) Utility of Nuclear Morphometry in Predicting Grades of Diffusely Infiltrating Gliomas.ISRN Oncology.

16. Mapstone NP, Zakhour HD (1990) Morphometric analysis of fine needle aspirates from breast lesions. Cytopathology 1: 349-355.

17. Boon ME, Trott PA, van Kaam H, Kurver PJ, Leach A, et al. (1982) Morphometry and cytodiagnosis of breast lesions. Virchows Arch A Pathol Anat Histol 396: 9-18.

18. Elzagheid A, Collan Y (2003) Fine needle aspiration biopsy of the breast. Value of nuclear morphometry after different sampling methods. Anal Quant Cytol Histol 25: 73-80.

19. Schöndorf $H$, Naujoks $H$ (1985) Determining the nuclear area in normal breas epithelia and in the nuclei of mammary carcinomas. J Cancer Res Clin Oncol 109: 241-244.

20. Pattari SK, Dey P and Ghoshal S (2000) Nuclear image morphometry and cytologic grade of breast carcinoma. Anal Quant Cytol Histol 22: 483-485. 